\title{
Formação Continuada em Educação Física: Relação entre Mundo do Trabalho, Políticas Educacionais e Educação
}

\author{
Elizara Carolina Marin* \\ Maristela da Silva Souza** \\ João Fracisco Magno Ribas ${ }^{* * *}$ \\ Marluce Raquel Decian ${ }^{* * * *}$ \\ Fabiane Rossato Herbst ${ }^{* * * *}$
}

\begin{abstract}
Resumo: Este artigo apresenta as ações e os resultados de um projeto de formação continuada desenvolvido entre os professores de Educação Física da região da Quarta Colônia e do CEFD/UFSM como também as implicações das políticas governamentais do estado do Rio Grande do Sul neste processo. A contextualização do projeto serviu como ponto de partida para elaborarmos uma discussão mais aprofundada sobre o que perpassa um processo de formação continuada, seus desafios, concepções e relações que se estabelecem entre Mundo do Trabalho, Políticas Educacionais e Educação. Palavras-chave: Prática profissional. Educação Física. Trabalho. Competência profissional.
\end{abstract}

\section{INTRODUÇÃO}

Partimos do princípio que a Educação Física é uma área constituída pelo movimento de diferentes conhecimentos científicos, caracterizando-a como uma disciplina conflituosa no que condiz a

\footnotetext{
${ }^{*}$ Centro de Educação Física e Desportos.Universidade Federal de Santa Maria. Santa Maria, RS, Brasil. E-mail: elizaracarol@yahoo.com.br

${ }^{* *}$ Centro de Educação Física e Desportos.Universidade Federal de Santa Maria. Santa Maria, RS, Brasil. E-mail: souzamaris@bol.com.br

${ }^{* * *}$ Centro de Educação Física e Desportos. Universidade Federal de Santa Maria. Santa Maria, RS, Brasil. E-mail : ribasjfm@hotmail.com

${ }^{* * *}$ Centro de Educação Física e Desportos. Universidade Federal de Santa Maria. Santa Maria, RS, Brasil. E-mail: marlucedecian@bol.com.br

${ }^{* * * \star *}$ Centro de Educação Física e Desportos. Universidade Federal de Santa Maria. Santa Maria, RS, Brasil. E-mail: fabianeherbst@terra.com.br

${ }^{\star \star \star \star *}$ Centro de Educação Física e Desportos. Universidade Federal de Santa Maria. Santa Maria, RS, Brasil. E-mail: fabianeherbst@terra.com.br
} 
sua prática pedagógica. Esta questão torna-se clara somente quando percorremos a história da Educação Física e percebemos que diferentes concepções foram expressadas nos seus momentos de construção. De uma prática higienista, militarista, competitivista, pedagogicista, (GUIRALDELLI JR., 1988), formaram-se várias críticas de cunho teórico, o que a conduziu, a partir dos anos de 1980, à elaboração de propostas de caráter crítico-transformador; a partir de então, ela vem propondo mudança na realidade concreta.

Porém, o conteúdo da mudança também se alicerça para além dos conhecimentos específicos. Isto implica pensar coletivamente o papel dos professores, de modo a que fique claro o compromisso social destes junto a seus alunos, ao facilitarem a apropriação do conhecimento.

Deste modo, fica evidente a necessidade de largos investimentos em pesquisa, estudos, propostas e ações variadas que visem, não só compreender, mas também contribuir para efetivas transformações.

Partindo-se do pressuposto de que a discussão e as ações com a Formação Continuada seja um caminho necessário para este processo, um grupo de docentes do Centro de Educação Física e Desportos da Universidade Federal de Santa Maria elaborou um projeto de pesquisa e extensão para promover a Formação Continuada de professores de Educação Física que atuam na Rede Pública Municipal e Estadual de uma região adjacente à cidade de Santa Maria, denominada Quarta Colônia ${ }^{1}$.

\footnotetext{
${ }^{1} \mathrm{~A}$ Quarta Colônia é uma região fundamentalmente marcada tanto pelo trabalho agrícola quanto pela religiosidade. A instituição escolar recebeu da lgreja forte impulso para expansão e organização. Atualmente, os governos municipais (principalmente ensino fundamental de $1^{\frac{a}{a}}$ a $4^{\mathrm{a}}$ série) e estaduais (principalmente ensino fundamental de $5^{\mathrm{a}}$ a $8^{\mathrm{a}}$ série e ensino médio) passaram a assumir e a gerenciar a instituição escolar na região; todavia, os valores cultivados, as condições socioeconômicas e a distância de centros urbanos marcam e influenciam o cotidiano escolar e o fazer pedagógico. A região engloba nove municípios, a saber: Ivorá, Silveira Martins, São João do Polêsine, Faxinal do Soturno, Dona Francisca, Pinhal Grande, Nova Palma, Agudo, Restinga Seca.
} 
Entendemos que uma proposta de formação continuada não tem um período delimitado para sua conclusão, pois as ações desenvolvidas devem adquirir um caráter duradouro e contínuo e devem vigorar como parte do conjunto das práticas cotidianas tanto do contexto da escola, como da universidade. Porém, como veremos no decorrer do artigo, após três anos de trabalho, fomos impossibilitados de dar continuidade ao processo. As ações governamentais do Estado do Rio Grande do Sul desdobraram-se em implicações diretas para o processo de formação continuada.

Com esta experiência, portanto, visualizamos que democratizar o conhecimento historicamente acumulado sugere discussão em torno das políticas públicas e dos pressupostos que orientam a prática pedagógica. Muitas vezes, o poder público, sob a apropriação do discurso crítico, apresenta projetos constituídos por práticas corporativistas e articulados com forças centralizadoras da sociedade.

Entendemos que a oferta de um processo de formação continuada passa pela necessidade de compreender o movimento teórico-ideológico de luta que se expressa no contexto educacional, de maneira que possamos distinguir as ações que se apresentam como sendo defensoras dos interesses coletivos daquelas carregadas de imposições originadas pela ideologia do capital.

Neste artigo, em um primeiro momento apresentamos as ações e as avaliações desenvolvidas no projeto de formação continuada nos anos de 2007, 2008 e 2009. A contextualização do projeto serviu como ponto de partida para elaborarmos uma discussão mais aprofundada sobre o que perpassa um processo de formação continuada, seus desafios, concepções e as relações que se estabelecem entre Mundo do Trabalho, Políticas Educacionais e Educação. 


\section{PROCESSO DE FORMAÇÃO CONTINUADA}

Uma das críticas mais comuns dirigidas aos programas de Formação Continuada incide na elaboração de propostas que, sem a participação dos docentes, são impostas. Em geral, são organizadas por empresas com fins lucrativos que se especializam na oferta de cursos de capacitação em forma de "pacote fechado", privilegiando técnicas e produtos. Somamos a este modelo os pacotes de formação que chegam às escolas através de políticas governamentais. Através da mediação das políticas públicas, o contexto educacional apresentase como foco privilegiado de implantação de perspectivas desejadas, demonstrando uma relação dialeticamente estabelecida entre o contexto de formação escolar e o contexto sócio-histórico. Isso demonstra que a educação não somente acompanha o movimento da sociedade, mas também se organiza a partir de suas demandas e para as suas demandas. Assim, tal movimento se estabelece por meio do exercício de luta ideológica, pois as demandas sociais, na maioria das vezes, condizem com os interesses de uma privilegiada minoria.

A experiência que ora apresentamos demonstra esse conflito entre diferentes projetos ideológicos nos quais as políticas governamentais, especificamente as do Estado do Rio Grande do Sul, intervieram em um projeto de formação continuada que se caracterizava como contínuo, coletivo e superador, implantando um processo de formação condizente com a lógica do mercado, isto é, que reduz a função da escola à formação de recursos humanos para manter a estrutura de um mundo do trabalho repleto de contradições. Tais contradições, então, se expressam na formação de sujeitos com competências para atuar em um campo de trabalho onde impera o subemprego e é regido por falta e ou pela supressão dos direitos trabalhistas já assegurados.

Entendemos que a finalidade da Formação Continuada é construir um conhecimento coletivo gerado a partir das necessidades históricas, sob os aspectos das experiências de vida pessoal e 
profissional, e dos conhecimentos historicamente construídos, contribuindo para promover mudanças nas práticas coletivas.

Para a elaboração da proposta de Formação Continuada dos professores da Quarta Colônia, no ano de 2006, nas escolas desta região, foi realizada uma pesquisa ${ }^{2}$ para que fosse possível compreender a dinâmica institucionalizada, tanto do trabalho escolar quanto do professor. Vale salientar o fato de que os municípios, campo das ações e da pesquisa, têm predominantemente como base econômica, social e cultural, características rurais. A escolha deste locus, portanto, não se deu ao acaso, mas sim por percebermos a necessidade de compreender como as especificidades e marcas locais influenciam as práticas escolares.

Com as informações obtidas nessa pesquisa conseguimos compreender um conjunto de elementos sobre o contexto local que nos orientaram na elaboração da proposta formativa para o ano de 2007.

Objetivando atender ao coletivo de professores, estruturou-se um processo que, com a concordância das direções das Escolas Estaduais e Secretarias Municipais, passou a compor as atividades didáticas dos professores e, portanto, o calendário letivo escolar de 2007. Por sugestão da maioria dos professores definiu-se um encontro a cada mês, que foram realizados nos diferentes municípios (num sistema de rodízio) com o fim de aproximação dos contextos escolares dos professores envolvidos no processo.

A proposta pautou-se por utilizar estratégias pedagógicas que visassem à interação e troca de experiências entre o coletivo de professores, de leitura e de discussão de textos, e de oficinas e de palestras sobre os seguintes conteúdos: organização do trabalho pedagógico da Educação Física Escolar; o conhecimento de que trata a Educação Física no contexto Escolar; jogos e esportes escolares; o esporte no contexto da sociedade atual.

\footnotetext{
${ }^{2} E m$ resumo, as principais dificuldades na atuação pedagógica vivenciada pelos professores pesquisados referem-se, de modo articulado, ao contexto político e econômico, às relações estabelecidas no contexto escolar e ao trato da disciplina. (MARIN, et. al.,2010).
} 
Os temas foram mediados por professores do Centro de Educação Física e Desportos segundo a especificidade da sua formação e da sua atuação e por professores convidados de outras universidades brasileiras. Contou-se no ano de $2007 \mathrm{com}$ o acompanhamento sistemático das Coordenadoras do projeto e de alunos da graduação, bem como de um gestor educacional da $8^{\mathrm{a}}$ Coordenadoria Regional de Educação (CRE) com o objetivo de subsidiar informações sobre o contexto da profissão no estado do Rio Grande do Sul.

A estratégia de gestão da Formação Continuada e de formulações teórico-metodológicas foi operada nas reuniões mensais entre os professores formadores e alunos da graduação envolvidos no processo. Como procedimento metodológico, em cada encontro foram utilizadas fichas avaliativas do processo formativo no percurso de 2007, 2008 e 2009 o que objetivou identificar de que modo os professores avaliavam os encontros no que tange a: espaço e tempo de duração; contribuições para a prática pedagógica; e se o formador atingiu os objetivos propostos.

Outro procedimento metodológico de importante avaliação do processo de formação foi o Grupo Focal, realizado no último encontro do ano de 2007 e 2008. Trata-se de um diálogo entre o grupo, mediado por um roteiro de problematizações referentes às influências da Formação Continuada na prática pedagógica; as motivações profissionais/pessoais que levaram a participar do processo de Formação Continuada em 2007 e 2008 e o que levaria a continuarem participando; as limitações que influenciaram sua participação nesse processo formativo; problemas vivenciados na prática pedagógica que gostaria que fossem contemplados na continuidade do processo; e sugestões para a organização e desenvolvimento da metodologia na continuidade das ações formativas.

Os diferentes procedimentos de avaliação adotados no ano de 2007 demonstraram efetividade no processo de formação. A assiduidade e a participação no percurso foi um demonstrativo, pois 
a freqüência se manteve até o último encontro, havendo evasão de $13,88 \%$, ou seja, de cinco (5) professores, evidenciando que se formaram vínculos que os fizeram permanecer e, como demonstra a avaliação do último encontro, a planejar a continuidade para 2008.

Além do processo de materialização dos nossos objetivos, apresentados anteriormente, nós nos propusemos a contribuir para a superação dos problemas pedagógicos encontrados pelos professores. A avaliação de 2007 resultou em algumas decisões que definimos serem essenciais para a continuidade do projeto, e principalmente para o seu aprofundamento, já que entendemos que uma formação para ser continuada deve realizar saltos qualitativos em seu desenvolvimento.

Primeiramente, entendemos que, para a realização de um trabalho coletivo, deveríamos fortalecer as relações entre Escolas, Universidade, Secretarias Municipais e Coordenadorias de Educação para que, juntas, e de maneira indissociada, se possa qualificar o contexto da educação.

Outro aspecto a ser considerado foi o tempo de realização dos encontros que, após análise, o grupo definiu por ampliá-lo para três (3) horas de duração uma vez por mês, sendo mediado por leitura de textos e discussões entre o grupo de professores nos municípios.

Quanto aos conteúdos norteadores da proposta de formação desenvolvida no ano de 2008, consideramos necessário o debate em torno da organização escolar, do projeto político pedagógico e da Seleção/Sistematização de Conteúdos.

Assim, a partir do construído no ano de 2007, apresentamos uma proposta de estudo de determinados princípios que, no processo de discussão e entendimento no grupo, possibilitaria a apreensão dos processos contraditórios da realidade escolar e, portanto, a superação de problemas da realidade cotidiana da área da Educação Física Escolar. 
A inserção do grupo formador na região da Quarta Colônia e a construção de um programa partilhado de formação continuada foi um processo considerado em constante movimento e que precisou ser repensado em diversos momentos, o que demonstrou o alto grau de envolvimento de seus participantes.

A prática pedagógica e a formação continuada ofereceram aos professores suporte para atuarem no cotidiano das aulas. No entanto, não se nega que a rotina do trabalho docente, o distanciamento do conhecimento produzido sobre o ensino - que muitas vezes ocorre na vida profissional do professor - e o isolamento do trabalho em sala de aula podem, em conjunto, produzir práticas cristalizadas, calcadas em modelos pré-determinados.

Um dos grandes desafios a que o grupo formador se propôs foi proporcionar aos professores uma reflexão sobre suas práticas. Isto foi feito com base em pressupostos teórico-metodológicos de autores como Bracht (2002) e Kunz (1991), e de obras como Soares et al. (1992). Alguns conflitos, gerados a partir da base teórica desenvolvida com o grupo, foram motivos da quebra de certezas presentes na prática cotidiana: dúvidas começaram a surgir, e por fim evidenciouse no processo uma desestruturação de alguns conceitos, métodos e modelos pré-estabelecidos, para dar lugar a novos conhecimentos.

Após dois anos de processo, iniciamos em 2009 ainda com $70 \%$ dos professores comprometidos com o desafio de concretizar o par dialético teoria/prática e construir uma proposta de conteúdos da Educação Física Escolar, primeiramente para o Ensino Fundamental. Porém, nesse mesmo ano, dificuldades impediram de se conciliar o processo em função das determinações do governo do estado, embargando a realização da formação continuada fora do horário de trabalho. Assim, as dificuldades individuais somadas à falta de transporte, já que o transporte público era disponibilizado por algumas secretarias municipais, mais as determinações institucionais formaram um conjunto de agravantes que desarticulou o coletivo de professores. 
Evidenciou-se, em todo o processo de formação, que o desenvolvimento profissional está intimamente relacionado com as políticas que assegurem legal e juridicamente a carreira docente, tal como a progressão funcional e o próprio duo tempo-espaço para a formação. Este aspecto foi crucial no processo. Várias determinações $^{3}$ foram estabelecidas - na gestão 2007/2010 - pela Secretaria de Educação do Estado do Rio Grande do Sul. Uma delas, a que se apresenta diretamente relacionada ao processo de formação continuada, diz respeito a um oficio circular de 19 de outubro de 2007 (ESTADO DO RIO GRANDE DO SUL, 2007) determinando que:

[...] não serão válidos para fins de Promoção, Encontros e Cursos realizados por professores e especialistas dentro do seu horário de trabalho e que o mesmo evento (encontro/curso) não pode ser duplamente certificado, devendo haver a opção por um ou outro. (grifo nosso)

Esse documento expressa claramente contradição entre o que diz a Lei de Diretrizes e Bases (1996, p.46) no artigo 61 o qual determina que:

[...]a formação de profissionais da educação, de modo a atender aos objetivos dos diferentes níveis e modalidades de ensino [...], terá como fundamentos: I - a associação entre teorias e práticas, inclusive mediante a capacitação em serviço" (grifo nosso).

Vale ainda destacar que tal determinação legislativa gerou uma considerável evasão de professores envolvidos no processo de formação continuada, em virtude de que os certificados não mais teriam validade.

A referida política educacional posta em prática pela Secretaria de Educação do Estado do Rio Grande do Sul trouxe implicações

\footnotetext{
${ }^{3}$ Tais como: fechamento de escolas e de centenas de turmas do Ensino de Jovens e adultos (EJA); aumento da carga horária do professor frente aluno; redução drástica da carga horária de preparação pedagógica; e enturmação - aumento da quantidade de alunos por sala de aula, através de um cálculo que estabelece o número de alunos por $\mathrm{m}^{2}$.
} 
diretas no processo de formação deste grupo de professores, demonstrando a luta que se estabelece no contexto educacional em que, de um lado, faz-se presente um processo de formação que objetiva a qualidade do ensino e a valorização do professor, e de outro, a desqualificação do ensino e a precarização do trabalho docente.

A seguir analisaremos esta contradição, que se orienta na luta ideológica contemporânea e que, no contexto da educação, manifestase nas características que o sistema capitalista impõe às atividades da escola, usando-a como mediadora para democratizar um determinado Projeto Histórico para a formação de um determinado Sujeito para um determinado Mundo do Trabalho.

\section{Mundo do tRabalho Versus políticas educacionals e eduCAÇÃo}

Quando nos propusemos a pensar, sistematizar e desenvolver um processo de formação continuada foi que passamos a perceber o vínculo com todo o contexto social que a determina e é por ela determinada. Para tanto, torna-se necessário compreender o trabalho do professor para além do cumprimento de suas horas de trabalho em sala de aula, frente aos alunos, e contextualizá-lo nas relações do mundo do trabalho, questionando tanto os objetivos que a lógica do capital apresenta para a educação, como também o papel das políticas educacionais neste processo.

Com o objetivo de manter a lógica do acúmulo do capital nas mãos de poucos, o capitalismo apresenta como uma de suas características cruciais atravessar várias crises estruturais e, a cada nova manifestação de crise, lutar para sua superação e a própria reordenação. No atual momento, a crise da década de setenta é a que manteve relações mais próximas com as conformações atuais ocorridas no mundo do trabalho. O esgotamento do Estado de BemEstar Social, conjugado ao esgotamento do padrão de acumulação fordista-taylorista e a volta de um "novo" liberalismo exigem 
continuamente diminuição do trabalho assalariado clássico e a expansão do trabalho parcial, temporário, informal, subcontratado, ou seja, flexível e precarizado.

Para isso faz-se necessária uma formação para um novo tipo de trabalhador também mais flexível, polivalente e dotado de competências para que possa se adaptar ao campo da empregabilidade. A Educação, diante dessas mudanças, também passa por um reordenamento e a escola aqui tem um papel fundamental, tanto na formação técnica quanto no âmbito ideológico da formação humana. Expressões do tipo: "Meu filho vai estudar para ser alguém na vida"; "Para conseguir um bom emprego" evidenciam verdades axiomáticas. A escola passa a ser uma referência enquanto locus que proporciona condições objetivas para preparar o indivíduo para a vida. Desse modo, a educação tem a função de adequar o indivíduo à sociedade para que, nesta, o sujeito possa adquirir seu lugar. Sob esta perspectiva, cabe aos educadores conhecer a realidade, não apenas para criticá-la e transformá-la, mas também para repassar aos educandos as competências e os valores demandados pela lógica da orientação capitalista. Como parafraseia Sader (2005, p.17), "digam-me onde está o trabalho em um tipo de sociedade e eu te direi onde está a educação".

A educação atualmente encontra-se pautada no fato de que vivemos em uma sociedade dinâmica que tem como marca indiscutível a produção constante e rápida de conhecimentos e que um bom trabalhador, para acompanhar este movimento, deve adquirir o conhecimento do que Sanches Gamboa (2003) chama de novas ondas tecnicistas ditadas pela informática e pela microeletrônica. $\mathrm{O}$ autor questiona o significado dessas dinâmicas e o sentido dessas novas revoluções tecnológicas que se anunciam como revolucionárias no meio do clamor desse novo milenarismo. Qual a nova sociedade que anunciam?

Sanches Gamboa (2003) salienta que uma revolução tecnológica de conjunto não se reduz à revolução de instrumentos de trabalho, mas atua também na estrutura dos processos produtivos. O que vemos através da revolução informacional que tem desenvolvido e 
potencializado o trabalho e a comunicação entre sujeitos é a permanência das formas de organização social e das relações de propriedade que regem "a sociedade nos moldes da propriedade privada e a acumulação ampliada da riqueza gerada pelos processos produzidos por um reduzido número de capitalistas".

Ao discutir essa questão, Duarte (2003) diz que para dar conta dessa tarefa, há necessidade de formação de um sujeito polivalente, isto é: múltiplo em competências. Para isso, a educação apresenta o "aprender a aprender" como síntese de uma educação destinada a formar indivíduos criativos. Porém, chama a atenção para um detalhe fundamental: a criatividade ensejada por esse projeto educacional não se confunde com busca de transformações da realidade social e, sim, "[...] criatividade em termos de capacidade de encontrar novas formas de ação que permitam melhor adaptação aos ditames da sociedade capitalista". (DUARTE, 2003, p.12)

A partir dessa nova demanda, se a escola colabora para a empregabilidade, ela assume uma dupla tarefa. Gentili (1999, p.89) declara que a impossibilidade de emprego para todos leva à constatação de que educar para o emprego requer também educar para o desemprego, gerando uma lógica de desenvolvimento que transforma a "dupla 'trabalho/ausência de trabalho' num matrimônio inseparável".

Para dar conta do lema "aprender a aprender" e colocar em prática as ações políticas mais amplas, a partir da Conferência "Educação para todos" realizada em 1990, a Organização das Nações Unidas para a Ciência, a Educação e a Cultura (UNESCO) gerou um documento, que foi elaborado por especialistas de todo o mundo e coordenado por Jacques Delors, que apresenta os quatro pilares da Aprendizagem: [1] aprender a viver junto; [2] aprender a conhecer; [3] aprender a fazer; [4] aprender a ser - no sentido de orientar as reformas curriculares nacionais. De acordo com Delors et al (1990, p.85), "[...] a educação deve simultaneamente fornecer mapas de um mundo complexo em constante agitação". Isto é, deve ser além do mapa também "a bússola" que irá permitir às pessoas encontrar seu caminho. 
Melo (2004, p.200), ao analisar o documento, conclui que:

O programa de educação para todos, impulsionado pelo BM e pela UNESCO, em que se baseiam as mudanças nas políticas educacionais para a América Latina e Caribe, principalmente a partir dos anos 90, é um programa de educação seletiva para as massas. 'Para as massas', sendo dirigido prioritariamente para a maioria da população, para os pobres, para os que vão exercer, no máximo, trabalho simples, durante toda a vida. 'Seletiva', porque a priorização da educação básica envolve uma restrição às 'necessidades básicas de aprendizagem', pois sua focalização também expressa uma 'desfocalização' em relação aos outros níveis de ensino.

No Brasil, esse documento foi publicado em 1998, com apoio do Ministério da Educação. No Rio Grande do Sul, de acordo com Baccin (2010), a implantação de políticas educacionais de viés neoliberal aparece com toda a força na gestão governamental 1995/ 1998. Porém, é na gestão 2007-2010 que o documento elaborado pela UNESCO é profundamente destacado. Vale citar o programa Boa Escola para Todos e os projetos: Professor Nota 10 - Valorizando o Magistério e o Sistema de Avaliação Externa do Rio Grande do Sul (SAERS). Juntamente com esses dois projetos, Baccin (2010) cita o documento Lições do Rio Grande, que consiste na construção de referenciais curriculares baseados na formação de competências. Sobre este documento, não cabe aqui uma análise do seu conteúdo; nossa crítica refere-se à ordem mais geral das políticas educacionais que, em nome de atender ao desenvolvimento de determinadas competências exigidas pelo mercado de trabalho, ferem diretamente a autonomia da escola.

$\mathrm{Na}$ introdução dos cadernos de Lições do Rio Grande (2009, p 10) afirma-se que:

A autonomia pedagógica da escola consiste na liberdade de escolher o método de ensino, em sua livre opção didático-metodológica, mas não no 
direito de não ensinar, de não levar os alunos ao desenvolvimento daquelas habilidades e competências cognitivas ou de não abordar aqueles conteúdos curriculares (Rio Grande do Sul, 2009).

Perguntamos "onde se encontra a possibilidade de organização do trabalho pedagógico da escola?", se os dirigentes escolares, professores e alunos não têm a liberdade de criar princípios curriculares nem a possibilidade de dialogar com as secretarias de educação sobre os conteúdos e competências a serem desenvolvidos no seu contexto de ensino.

Baccin (2010), ao analisar as políticas do estado do Rio Grande do Sul, gestão 2007-2010, constata, entre outras questões, que na relação entre capital e trabalho, as referidas políticas educacionais sofrem influência direta dos organismos internacionais, tais como Banco Mundial (BM), Fundo Monetário Internacional (FMI) e Organização das Nações Unidas (ONU), demonstrando que tais políticas estão sendo implementadas na tentativa de colaborar na superação das sucessivas crises que o modo de produção capitalista perpassa.

A autora salienta que a gestão em análise, através das políticas educacionais implementadas, dificulta as possibilidades de outra organização do trabalho pedagógico que não seja a que atenda à alienação.

Assim, ao desenvolver as políticas educacionais, tal governo mantém uma organização do trabalho pedagógico que assume os contornos necessários para atingir os objetivos da escola capitalista, ou seja, que contribui para a manutenção da estrutura de exploração. (BACCIN, 2010, p.71).

Foi neste contexto de políticas educacionais que o projeto de formação continuada entre os professores da região da Quarta Colônia e do CEFD/UFSM se desenvolveu e perdeu espaço. 
As políticas educacionais do estado do Rio Grande do Sul chegaram ao ambiente escolar através de vídeos (programa dos quatro pilares da educação) e de cadernos didáticos (as lições do Rio Grande), sendo indicadas para orientar os planos de estudo e as propostas de ensino dos professores.

Além de tratar-se de políticas inseridas em um projeto histórico que atende aos objetivos de manutenção do atual modo de produção e organização do trabalho, são políticas implementadas de cima para baixo, desconsiderando questões básicas e fundamentais em um processo de formação, como o contexto de inserção da escola, a organização do trabalho pedagógico da própria escola, o conhecimento acumulado dos professores, suas experiências e necessidades.

Especialmente se tratando da região da Quarta Colônia, entendemos que, no governo do Estado do Rio Grande do Sul tais políticas educacionais foram planejadas e aplicadas sem levarem em conta a cultura local, as necessidades e dificuldades vividas pelos professores, como também e de forma muito grave, desconsideraram o processo de formação continuada que esses professores estavam vivenciando e o sentido do conhecimento construído nesse processo, já concretizado no fazer diário da prática pedagógica.

\section{Considerações finaIS}

A partir do exposto, percebemos uma relação dialeticamente estabelecida entre a formação continuada e o mundo do trabalho, sendo as políticas educacionais mediadoras nesse processo. $\mathrm{Na}$ experiência apresentada, tornam-se evidentes as contradições que orientam o processo de formação docente, em que, de um lado, se apresentam possibilidades de saltos qualitativos no processo educacional, e de outro se evidencia a precarização do ensino.

O Plano Estadual de Educação do Estado do Rio Grande do Sul estabelece que a valorização do magistério se dê a partir de ações voltadas à qualificação da formação dos professores, assim 
como à melhoria de suas condições de trabalho. Outro aspecto importante se refere à relação estabelecida entre a valorização do magistério e a constituição e/ou atualização dos Planos de Carreira do Magistério Público contemplando em seu texto a promoção por meio da participação em processos de formação continuada.

Como se pode observar está evidenciado na legislação estadual as responsabilidades reconhecidas pelo sistema de ensino, assim como as parcerias por eles reconhecidas como promissoras para a institucionalização de políticas mais efetivas e duradouras, no que tange ao desenvolvimento profissional dos professores e a conseqüente melhoria da qualidade do ensino.

Porém, aproveitando-se de tal direito, o governo (gestão 20072010), sob decreto, destrói os direitos já garantidos e instala suas propostas, desconsiderando o legado encontrado na escola e acirrando a fragmentação do saber e o silenciamento dos professores.

Este processo nos leva a entender juntamente com Duarte (2006) que ao mesmo tempo em que o capitalismo, através do seu sistema produtivo, exige a elevação do nível intelectual dos trabalhadores para que estes possam acompanhar as mudanças em curso, essa elevação intelectual precisa, sob a ótica da classe que domina, ser limitada no sentido de evitar que os trabalhadores utilizem o conhecimento como instrumento de luta "por uma radical transformação das relações sociais de produção" (Duarte, 2006, p.6).

A impossibilidade de continuidade do trabalho de formação, objeto deste artigo, por ocasião das políticas implementadas pelo estado do Rio Grande do Sul, demonstra a desconsideração com as ações em andamento e a falta de diálogo com o coletivo dos professores do estado por parte do poder público.

Ações isoladas não dão conta das necessidades do contexto educacional e menos, ainda, propostas que se apresentam como "lições". Entendemos que o sucesso do desenvolvimento de propostas de formação continuada deve ligar valorização docente considerando sua formação básica e em serviço, ao poder público que possibilita condições estruturais de tempo e salário, como também 
o compromisso das instituições públicas formadoras de professores.

Portanto, é nessas circunstâncias que propomos o debate em torno da formação continuada e convidamos o poder público, escolas e universidades para este compromisso. 
Continuing Education: Relationship between the World of Work, Education and Educational Policies

Abstract: This article presents the actions and the results of a continuing education among physical education teachers in the region of Fourth Cologne and the SPDC/ UFSM as well as the consequences of government policies in the state of Rio Grande do Sul in this process. The contextualization of the project serves as a starting point for developing further discussion about what goes through a process of continuing education, its challenges, concepts and the relationships established between the World of Work, Education and Education Policies.

Keywords: Professional practice. Physical education. Work. Professional competence.

\section{Formación Continuada en Educación Física:} Relaciones entre el Mundo del Trabajo, Políticas Educacionales y Educación

Resumen: Este artículo presenta las acciones y los resultados de un proyecto de educación continua entre los profesores de Educación Física en la región de la Cuarta Colonia y del CEFD/ UFSM como también las consecuencias de las políticas gubernamentales en el estado de Rio Grande do Sul en este proceso. La contextualización del proyecto sirve como punto de partida para la elaboración de continuar el debate sobre lo que pasa por un proceso de educación continua, sus desafíos, los conceptos y las relaciones establecidas entre el mundo del trabajo, Educación y Política Educativa.

Palabras clave: Práctica profesional. Educación física. Trabajo. Competência profesional. 


\section{REFERÊNCIAS}

BACCIN, Ecléa Vanessa Canei. Educação física escolar: implicações das políticas educacionais na organização do trabalho pedagógico. 2010. 135 f. Dissertação (Mestrado em Educação). Programa de Pós-Graduação em Educação Física, UFP, Pelotas (RS), 2010.

BRACHT, Valter et al. A prática pedagógica em Educação Física: a mudança a partir da pesquisa-ação. Revista Brasileira das Ciências do Esporte, Campinas v.23, n.2, p.9-29. jan. 2002.

BRASIL. [Lei Darcy Ribeiro (1996)]. LDB: Lei de Diretrizes e Bases da Educação Nacional: lei no 9.394, de 20 de dezembro de 1996, que estabelece as diretrizes e bases da educação nacional. - 5. d. - Brasília : Câmara dos Deputados, Coordenação, Edições Câmara, 2010. 60 p. (Série Legislação; n. 39)

DELORS, Jacques et al. Learning: The Treasure within. Paris: UNESCO, 1990. EFA Global Monitoring Report. Paris: UNESCO. Disponível em: htt:www.ibe.unesco.org/fileadmin/user.../PillarsLearningZhou.pdf. Acesso em: 14 maio 2010.

DUARTE, Newton. Sociedade do conhecimento ou sociedade das ilusões? Quatro ensaios crítico-dialéticos em filosofia da educação. Campinas,SP: Autores Associados, 2003.

DUARTE, Newton. Vigotski e o "aprender a aprender": crítica às apropriações neoliberais e pós-modernas da teoria vigotskiana. 4.ed. Campinas, SP: Autores Associados, 2006.

ESTADO DO RIO GRANDE DO SUL. Secretaria de Educação. Ofício Circular. COPROMAG/SE.01. Porto Alegre, 19 out. 2007.

GENTILI, Pablo. Educar para o desemprego: a desintegração da promessa integradora. In: FRIGOTTO, Gaudêncio (Org.). Educação e crise do trabalho: perspectivas de final de século. 3.ed. Petrópolis,RJ: Vozes, 1999. p.76-99.

GUIRALDELLI JR., Paulo. Educação Física Progressista: a Pedagogia CríticoSocial dos conteúdos e a Educação Física brasileira. São Paulo: Loyola, 1988.

KUNZ, Elenor. Educação Física: Ensino e Mudanças. Ijuí: Editora da UNIJUI, 1991.

MELO, Adriana Almeida Sales de. A mundialização da educação: consolidação do projeto neoliberal na América Latina, Brasil e Venezuela. Maceió: EDUFAL, 2004.

RIO GRANDE DO SUL. Lições do Rio Grande: referencial curricular para as escolas estaduais, 2009. Disponível em: http://www.educacao.rs.gov.br. Acesso: 08 mar. 2010. 
SADER, Emir. Prefácio. In: MÉSZÁROS, István. A Educação para além do capital. São Paulo: Boitempo, 2005.

SANCHEZ GAMBOA, Silvio. A globalização e os desafios da educação no limiar do novo século: Um olhar desde a América Latina. In: LOMBARDI, J.C. (org). Globalização, Pós-modernidade e Educação: história, filosofia e temas transversais. Campinas,SP: Autores Associados, 2003. p.79-106.

SOARES, Carmen Lúcia et al. . Metodologia do Ensino da Educação Física. São Paulo: Cortez, 1992.

Apoio financeiro: Fundo de Incentivo à Extensão - FIEX/UFSM; Programa de Licenciaturas - PROLICEN/UFSM

Endereço para correspondência:

Elizara Carolina Marin

Centro de Educação Física e Desportos,

Avenida Roraima, ㄲo 1000,

Cidade Universitária, Bairro Camobi, Santa Maria/RS,

CEP. 97105900.

elizaracarol@yahoo.com.br

Recebido em: 10.10.2010

Aprovado em: 19.06.2011

Movimento, Porto Alegre, v. 17, n. 02, p. 259-278, abr/jun de 2011. 
